\title{
La endoalteridad y su tratamiento Acerca de los consanguíneos depredadores en el México oriental*
}

\author{
The endoalterity and its treatment \\ Regarding the blood relative predators in eastern Mexico
}

\author{
JACQUES GALINIER**
}

\begin{abstract}
Among the Otomi of the eastern Sierra Madre mountain range, the question of alterity addresses the status of antagonistic beings interacting within the social space of the native community which encompasses both the ecosystem of the living and the domain occupied by the dwellers of the underworld. We emphasize the contrast between an exoalterity concerning all the foreign alteri, i.e. unknown people, and an endoalterity that includes threatening enemies originating from the very circle of commensality. Among the latter are the witches, some of whom are kin to those in the circle of commensality, on a quest for blood entailing the sacrifice of newborns, assimilated to the progeny of the Devil, in order to satisfy the predation of this vital substance, assimilated to semen, which is the preliminary condition leading to the revitalization of the cosmos, as expressed in a spectacular way by the octava ritual at the end of Carnival time.
\end{abstract}

Key words: carnival, exoalterity, witches, otomi, sacrifice, Devil

\begin{abstract}
Resumen
Entre los otomíes de la Sierra Madre Oriental, la cuestión de la alteridad abarca a la vez el ecosistema de los vivos y el dominio ocupado por los moradores del inframundo. Se pondrá énfasis en una exoalteridad, relativa a todos los alteri extranjeros, y en una endoalteridad, incluyendo a los enemigos amenazantes oriundos del mismo círculo de la comensalidad, entre los cuales destacan las brujas, ya que entre ellas figuran parientes cuya búsqueda de sangre implica el sacrificio de los recién nacidos, asimilados a la progenitura del diablo, por la depredación de la substancia vital, asimilada al semen, lo que resulta en la revitalización del cosmos, como lo expresa de manera espectacular el ritual de la octava, al final del Carnaval.
\end{abstract}

Palabras clave: Carnaval, exoalteridad, brujas, otomí, sacrificio, diablo

$\mathrm{H}$ istóricamente, en nuestra disciplina, la alteridad representa uno de los conceptos más problemáticos y, sin embargo, más fructíferos para contemplar el funcionamiento de los sistemas sociales que privilegian las divisiones elaboradas entre el aquí y el allá, nosotros y ellos. En fechas recientes, ha suscitado nutridas discusiones transdisciplinarias que asocian la reflexividad de la filosofía y la pragmática hermenéutica de la antropología, como lo subraya Leistle (2013). En Mesoamérica, las organizaciones dualistas aparecen como

\footnotetext{
* Artículo recibido el 19/09/19 y aceptado el 16/12/19.

** Centre National de la Recherche Scientifique, Laboratoire d'ethnologie et de sociologie comparative, Maison René -Ginouvès, 21, Allée de l'Université, 92023 Nanterre France <jacques.galinier@cnrs.fr>.
} 
una de las formas arquetípicas de articulación entre organizaciones sociales, parentesco y orden del universo (Van Zantwijk, de Ridder y Braakhuis, 1990; Davies, 1990). Analizaremos el caso de los otomíes del oriente, ${ }^{1}$ los cuales mantienen un abanico de sistemas de moitiés, con distintos niveles jerárquicos, en gran medida remodelados a raíz de la emergencia de barrios en la época colonial, los cuales ocultan en parte formas pretéritas de estructuración del espacio social (Galinier, 1990: 111-115). De hecho, quedan vigentes principios rectores de modelización del territorio, a partir de las oposiciones pueblo/ranchería, comunidad indígena/cabecera mestiza, espacio habitado/espacio salvaje, altiplano/Huasteca. En los colectivos humanos, la alteridad se expresa a través de la dicotomía entre hogâkhâi (gente buena) y s'o ra khâi (gente mala), oposición entre la población de la comunidad, "buena", es decir conocida, y la gente de otras comunidades, "mala", o desconocida.

En apariencia, esas dicotomías representarían la base intangible de una doxa compartida sobre la alteridad en su versión emic. Sin embargo, como lo mostrarán los casos que examinaremos, el valor heurístico de la alteridad resulta problemático: sería tal vez un concepto vacío si no se decanta a través de otras de sus características sociológicas. Esto es, la alteridad remite a la cuestión inquietante de la presencia de distintas clases de "enemigos" en la misma comunidad, incluso dentro del círculo de la comensalidad. Plantea formalmente el asunto del estatus de seres antagónicos dentro del espacio social de los pueblos nativos, que abarca a la vez el ecosistema de los vivos y el dominio ocupado por los moradores del inframundo.

Se revisará esta propuesta a partir de un estudio etnográfico de la zona otomí, llevado a cabo tanto en las comunidades del altiplano (Santa Ana Hueytlalpan, San Pedro Tlachichilco), como en los pueblos de la Sierra Alta y la Baja, hasta las comunidades veracruzanas de la Huasteca, del municipio de Ixhuatlán de Madero (Galinier, 1987). En numerosos artículos y en La mitad del mundo. Cuerpo y cosmos en los rituales otomíes (1990), he contemplado el rol rector del Carnaval en la construcción y la distribución de los géneros, y en los procesos de adscripción de la identidad (Galinier, 1990: 335-475). En este trabajo, la problemática consistirá en introducir al debate la importancia de la ideología de la depredación, que con anterioridad había pensado como el hilo conductor de la cosmovisión otomí, pero que exploraré teniendo como eje la circulación de sangre entre entidades agresivas y sus víctimas.

\section{Ein inneres Ausland o las entrañas de un cuerpo colonizado}

La primera dificultad al pensar la alteridad implica definir previamente las fronteras internas de la ipseidad, es decir, de la representación que una persona tiene de su singularidad, diferente de la de los demás humanos. La clave de esta aporía la detienen nuestros interlocutores chamanes, cuya reflexión sobre la ontogénesis confirma que no existe ningún fragmento del cuerpo humano que esté protegido, ninguna manera de considerar el cuerpo como una fortaleza inatacable. De hecho, resulta imprescindible articular a las fórmulas canónicas señaladas antes, las divisiones asociadas a las representaciones locales del esquema corporal, como marco de inscripción de polaridades básicas tales como: alto/bajo, izquierda/derecha, adelante/atrás y, sobre todo, la oposición interior/ exterior, es decir, entre lo que entra y lo que sale del cuerpo, división que desempeña un papel rector, porque gobierna la circulación de fuerzas que condicionan la ontogénesis de los sujetos (Galinier, 1990: 615-633). Por otra parte, la concepción de la persona otomí confirma una coincidencia total entre cuerpo físico, cuerpo social y cuerpo cósmico, los cuales son pensados en términos anatómicos, como lo comprueba el uso ritual de figurillas antropomorfas, los "ídolos". La multiplicidad de los cuerpos se articula dentro de constelaciones sociales (familiares, de comensalidad, de vecindad, o de enemistad). Como lo expresan Olavarría, Aguilar y Merino a propósito del cuerpo yaqui, el cuerpo otomí representa "el locus que, a través de sus propiedades, productos, partes y fluidos, es capaz de entablar relaciones con otros seres humanos" (Olavarría, Aguilar y Merino, 2009: 7). Según la doxa chamánica, el mundo está hecho de pieles, envueltas unas en otras, bajo la forma de matrioshkas, y esa sucesión de pieles (a las cuales remite la terminología de parentesco) determina la identidad de los individuos (Galinier, 1990: 127-131): así aparecen en el espacio clínico del experto ritual bajo la forma de "ídolos". El diablo otomí es una de ésas, la más eminente de todas, šimhoi: hace las veces de Dueño de las pieles,

\footnotetext{
1 Los otomíes del oriente son poblaciones indígenas del sur de la Huasteca, ubicadas desde los límites del altiplano central hasta las zonas de tierra caliente, en los estados de Hidalgo, Veracruz y Puebla. En este artículo, se comentarán materiales etnográficos relativos a los pueblos de la Sierra Alta, de los municipios de Tenango de Doria y San Bartolo Tutotepec, en cuya cabecera se realiza el ritual de la octava, discutido más adelante.
} 
y de su desollamiento. Por esas razones, el cuerpo otomí sirve de archivo, de memoria y soporte de un complejo sofisticado de representaciones oriundas del inframundo, que rige la etiología y la escatología, la ontogénesis y la filogénesis: su proyección en la naturaleza da cuenta de una cartografía fina del territorio, saturado de símbolos claves, cuyo repertorio aparece plasmado en imágenes de papel.

En varios escritos he comentado la dificultad de entender la identidad otomí sin considerar, como el poeta Rimbaud, que "Yo es otro", ${ }^{2}$ es decir, que en la construcción de la ontogénesis aparecen elementos literalmente ajenos al sujeto propio, incluso que pertenecen a colectivos enemigos, pero son indisociables de la persona propia, lo que complica la aprehensión del sujeto y la delineación de las fronteras de la alteridad (Galinier, 2009a: 213-226). Esta observación entra de forma directa en sintonía con la definición de lo reprimido (das Verdrängte) según Freud, concebido como una suerte de inneres Ausland, esto es, un territorio ajeno, pero interno a las envolturas corporales, y que funge como elemento de la construcción del Yo. ${ }^{3}$

Estas deliberaciones nos conducen a señalar que, en la Sierra Madre Oriental, la alteridad se descompone en una serie de elementos, articulados con el conflicto entre una endoalteridad vs. una exoalteridad. ¿De qué se trata finalmente? La exoalteridad es fácil de reconocer, porque remite a los colectivos enemigos físicos, tanto humanos como animales, vivos o ancestralizados. En cambio, la endoalteridad se aplica a los mismos sujetos humanos, teniendo en cuenta que son habitados por este "cuerpo ajeno", que limita su albedrío y es responsable de acciones malévolas, de la violencia, y de las pulsiones sexuales. El cuerpo humano es literalmente "actuado" por este segundo cuerpo, al cual remite para designar el conjunto corporal, el difrasismo mate okhâ, mate zithũ (mitad de dios, mitad del diablo) revelado por mis interlocutores, que sirve de lema para explicar el conflicto entre parte superior y parte inferior, para referirse a la zona crítica donde se ubican los órganos genitales y virtualmente "el viejo costal" (tözã), suerte de contenedor invisible de imágenes reprimidas que podríamos comparar con el inneres Ausland, de Freud. Hay que recordar además que tözã designa también a un actor del Carnaval, epítome paradigmático de la alteridad ${ }^{4}$ (Galinier, 1990: 342-346 y 2019a).

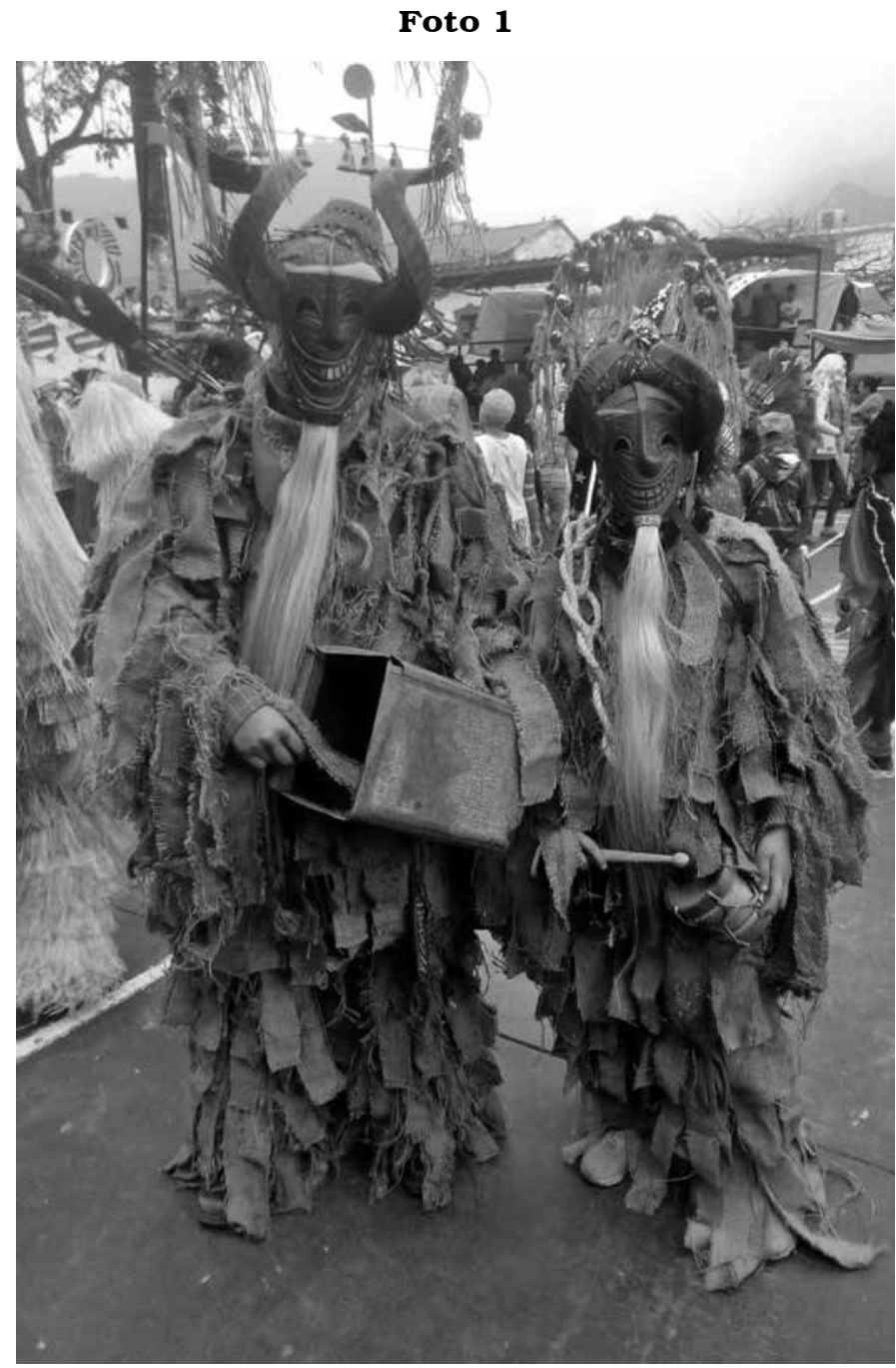

El viejo costal, tözã, figura arquetípica del Carnaval y envoltura síquica del cuerpo humano, San Bartolo Tutotepec, Hgo. Foto: J. Galinier

\section{Lógica de la depredación: la captación de sangre}

La alteridad parte de la construcción del sujeto desde su nacimiento, de un sujeto fracturado por una parte ajena que mantiene una relación conflictiva con la parte propia. En los casos que examinaremos, el punto medular de la problemática es el tratamiento de la depredación como resultante de la endoalteridad (es decir, la presencia de enemigos dentro del mismo

2 Carta de Arthur Rimbaud dirigida a Paul Demeny (15 de mayo de1871), en Rimbaud (1958: 305-306).

3 "Das Verdrängte ist aber für das Ich Ausland, inneres Ausland, so wie die Realität - gestatten Sie den ungewohnten Ausdruck - äußeres Ausland ist" (Freud, 1933: 60).

4 Esa idea de un segundo cuerpo incorporado en el cuerpo físico está muy extendida en Mesoamérica. Se verifica en particular entre los nahuas de Texcoco, para quienes este cuerpo se diferencia del cuerpo orgánico a partir de una oposición adentro/afuera (Lorente, 2011). 
círculo de parientes) y el hecho de que la consanguinización de los afines (transformados en "hijos" e "hijas" del ancestro apical, a través de mecanismos rituales como el Carnaval o la Fiesta de Muertos), no elimina la amenaza de la captación de sangre, teniendo en cuenta que la envidia es un factor de exacerbación de los conflictos dentro del parentesco. Para los otomíes, la depredación es un proceso universal, el motor de un "sacrificio" en todos los niveles del cosmos: es la condición del movimiento perpetuo de nzahki, la fuerza responsable de la vida en el ecosistema de la comunidad indígena. La amenaza es constante, permanente, más intensa en la oscuridad, cuando se esfuman las fronteras corporales, genéricas. Confirma la atomización de la persona y la fragmentación de sus componentes entre los soportes corporales y sus periferias humanas o animales: ntâhi (aire); šũti (sombra), zate (nahual), "espíritu".

En toda el área otomí, la circulación de sangre entre el interior y el exterior del cuerpo es la clave del proceso de construcción y de defensa de la identidad. Los seres responsables de esta depredación conforman una categoría de mujeres llamadas brujas, zönde (las que alumbran) o pöšhwai (las que clavan un machete). Pero ¿por qué las brujas se nutren exclusivamente de sangre? Justo porque captar sangre permite el equilibrio entre las energías intracorporales y extracorporales, considerando que sus propiedades regeneradoras compensan la pérdida de la sangre menstrual. Como emisarios del Viejo (Dueño del Carnaval y del Mundo, avatar del diablo, zithũ), las brujas se encargan de abastecerlo con este líquido sagrado. En la oscuridad, se transforman en pájaros, parecidos a garzas. De hecho, practican un autosacrificio reversible, por la ablación de sus piernas que depositan en la noche al pie del fogón, cuando los comensales están dormidos: brincan tres veces encima antes de volar en busca de la sangre de los recién nacidos, un tema clásico del nahualismo mesoamericano, señalado desde la época del contacto (Martínez González, 2011). Se cree que si un comensal, por lo general el cónyuge, despierta y se da cuenta de la presencia de las piernas al lado del fogón, las arroja en la lumbre. En consecuencia, la bruja no puede regresar a su forma inicial, lo que la condena a volar por toda la eternidad. La sangre del bebé contiene un potencial energético que sirve para alimentar a las brujas, de modo que, desde su nacimiento, la cría resulta ser una víctima virtual, mientras que el acto de volar funge como un modo de mantener una conexión entre dos mundos.

Los bebés son más vulnerables cuando tienen menos de un año, es decir, cuando su "olor" es más perceptible. Los días más propensos para los ataques de brujas son el martes y el jueves: hacen ruido cuando intentan penetrar en las casas, infiltrándose debajo de los techos de lámina. En Santa Mónica se comenta que las brujas son responsables de varias muertes a la vez, y que las víctimas pueden pertenecer a la misma familia. En consecuencia, las tijeras abiertas en la parte superior de la cuna permiten alejarlas, también ponen espinas alrededor de la casa para que no entren; otra posibilidad es ahumar chile seco, con lo que se logra ahuyentar a las brujas. En todo caso, esas precauciones se dirigen a depredadoras potenciales externas al círculo de la comensalidad, pero no eliminan la amenaza doméstica, relacionada con los parientes más cercanos.

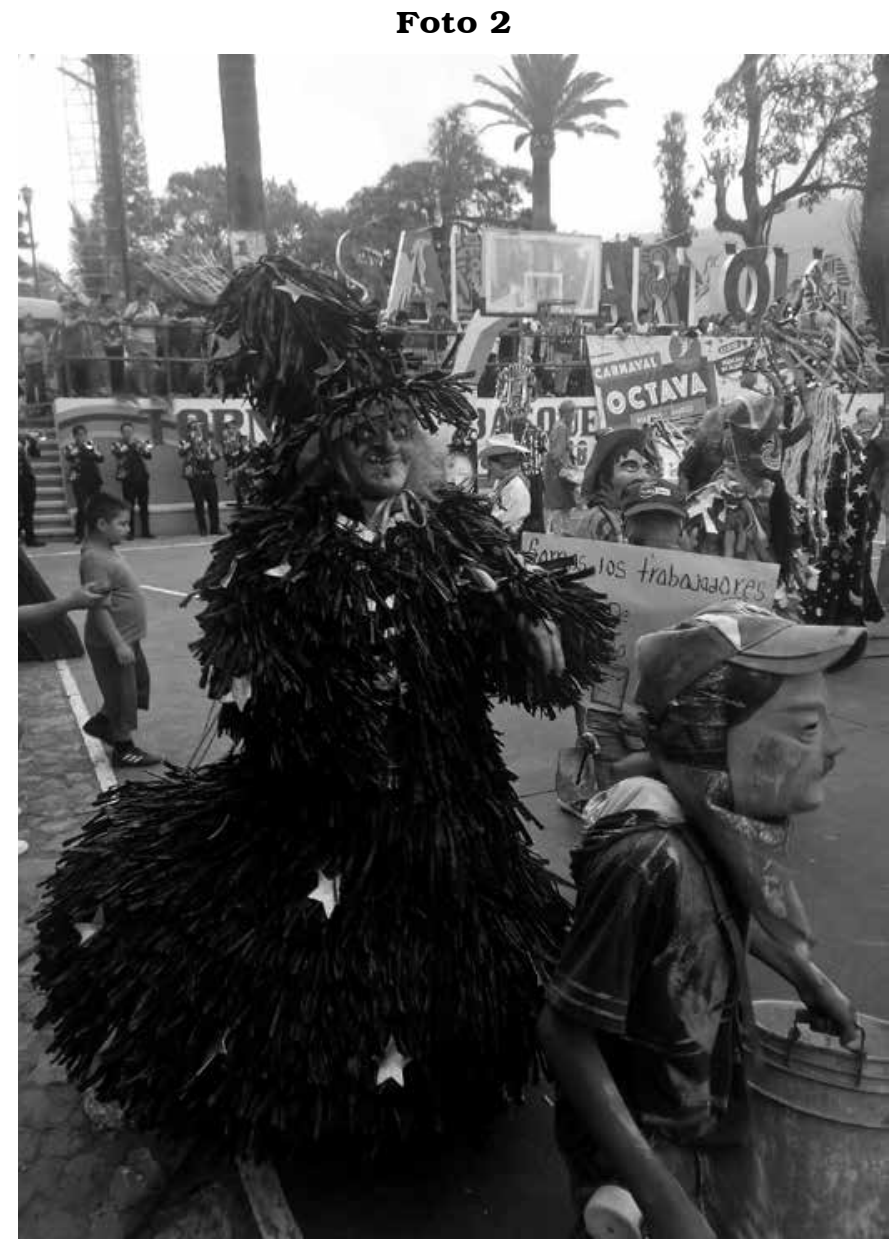

La bruja, epítome de la depredación y nueva figura emblemática del Carnaval, San Bartolo Tutotepec, Hgo. Foto: J. Galinier.

Las brujas participan de un macrosistema de alimentación y retroalimentación del cosmos que incluye a los nahuales y a los ancestros, y que se verifica a través del complejo ritual del Carnaval y de la Fiesta de Muertos. De hecho, el nahualismo otomí no está 
focalizado sólo en la coesencia y la copresencia de animales salvajes, cuyo destino resulta paralelo al de un ser humano determinado. Los animales domésticos son parte de este sistema de relaciones. Por su lado, si las brujas desempeñan un papel eminente en el Carnaval es porque cumplen con la función específica de matar, pero al servicio de la vida, del Viejo, fuente de toda existencia. En esas performances, todos los actores aparecen como miembros de una sola fratría (son los "hijos" del Viejo). Pero, ¿por qué son los consanguíneos las víctimas privilegiadas de las brujas? Porque todo el sistema ritual necesita de esos flujos de energía, y ¿por qué solamente las brujas son capacitadas para dirigir esta circulación entre el interior y el exterior de los cuerpos, del espacio doméstico y de la familia? En esta escena, el diablo o zithũ (el que come el nombre), aparece como el gran regulador, y a la vez el destinatario de la sangre, transmisor de la fuerza vital, nzahki, que circula por medio de la sangre o del semen, confundidos en una sola palabra, khi. Entre las entidades relacionadas con las brujas, se encuentran el guajolote, animal de tierra, y el zopilote, animal del cielo. El guajolote (koni, macho, y sukotu, hembra), ejerce entre los vivos su capacidad de seducción: de todos los animales domésticos es el que tiene los mejores atractivos. Por eso, las brujas se transforman en guajolotes. Su carúncula frontal, nyãšiyũ, los asocia con el diablo durante su fase de erección. Si uno anda vestido de rojo, los guajolotes machos y hembras lo corretean. Ahora, ¿serán los guajolotes que circulan en el solar, soportes de brujas, evidencias de tentativas nocturnas fracasadas de regreso al cuerpo inicial? Posiblemente, la forma guajolote es entonces el fruto de una experiencia transicional entre el espacio local y los espacios / tiempos exteriores. Se piensa que los guajolotes son los nahuales de uno. No obstante, se verifica una incertidumbre en cuanto a la relación entre un sujeto y su nahual, cuando se sacrifica un guajolote para celebrar la Fiesta de Muertos. Los "que saben”, bãdi o chamanes, conocen sus nahuales, animales de tierra y de aire. Antes de que amanezca, los guajolotes empiezan a hacer la rueda. Simbolizan la presencia de los alteri como miembros de la comunidad extensa de sujetos divididos.

El enigma de la transexualidad de las brujas plantea la cuestión de la inversión genérica (Galinier, 2019b). En la Sierra Madre Oriental, los nahuales tienen la capacidad de transformarse en animales de tierra o celestes, cada clase de animal practicando una depredación específica, por aspiración o manducación. Las brujas son el ejemplo más angustiante de la afirmación de ese tipo de endoalteridad, que no es nada más que una alteridad originaria, porque no pueden concebirse ontologías que no incluyan cierta presencia de características ajenas. El ritual prínceps (brincar encima del fogón) aparece como un dispositivo mecánico accesible para todos los sujetos, que pueden usar en función de sus estrategias personales de depredación.

El complejo de las brujas no debe entenderse como un epifenómeno marginal, sino como la clave de una cosmología nocturna, que abarca los fundamentos de la misma concepción de la vida. Es parte de un síndrome que no sólo afecta a las poblaciones nativas de la sierra, sino también a los mestizos. Sirve de parangón, de modelo explicativo de la desdicha biológica, de un sistema de causas y efectos, cuando la experiencia de la noche modifica las condiciones de control de su propio cuerpo. Las brujas pueden actuar de día, pero en esencia son actores de la noche. Todos los sujetos son aptos para emprender un viaje onírico instrumentalizado tras la performance de la ablación de las piernas. Por eso, en la oscuridad, se abren los componentes de la persona, e ipso facto las piernas pueden desarmarse, como a partir de un ensamblaje mecánico. La dimensión acústica de su presencia es un revelador de las excitaciones sensoriales y del halo de espanto en el cual están envueltas las víctimas. Así, el síndrome de las brujas demuestra los procesos de enajenación y de desterritorialización de los componentes del sujeto. Hace metáfora de una concepción global de la persona que articula los parámetros físico, fisiológico, simbólico social y cosmológico. De hecho, esta propuesta-que comparten las poblaciones mestizas de la sierra, como lo demuestra el trabajo de Caro Sevilla (2019) sobre la transformación en puxk'uai-es más que un simple cambio de apariencia y de especie: ubica las brujas en una posición de alteridad extrema, dentro de un paisaje cosmológico en el cual la noche funciona como tela de fondo de los procesos de transformación genérica, intra- e interespecies (Galinier, 2019b).

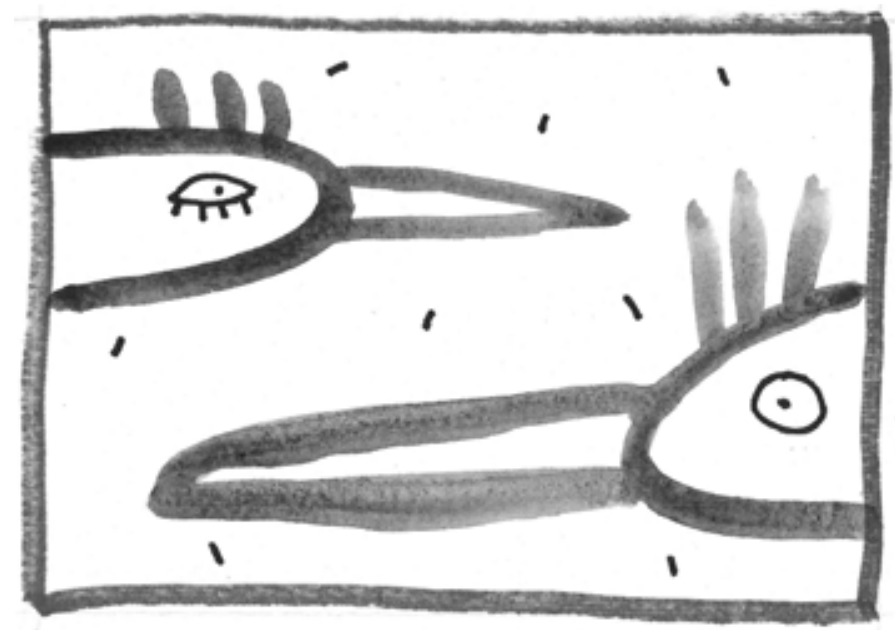




\section{Feto agresivo vs. coito sádico}

Para entender el estatus específico del feto y el destino ontológico del bebé es necesario remitirse al proceso ritual del Carnaval, porque implica una fecundación de parte del ancestro mayor, el Viejo (šihta: padre podrido) o diablo (zithũ), el embarazo de su pareja, la Vieja Madre (pömbe) y un alumbramiento del bebé, asimilado a un pequeño diablo (t'üzithũ), lo que significa que toda la concepción intrauterina es obra del Dueño del Mundo. Lo subrayan de manera explícita los cantos rituales: el Viejo metaforiza al pene como instrumento de fecundación y de recreación de la fuerza cósmica. ${ }^{5}$ Es decir que se ubica al principio del proceso de creación y en su conclusión, a través del nacimiento. Todas las prohibiciones de las mujeres grávidas confirman el monitoreo de la vida sexual y formativa del feto por el propio zithũ , avatar del astro lunar, cuya fuerza puede penetrar una mujer si ella se queda observándolo de manera prolongada, y atacar al feto.

Ahora, ¿cómo relacionar la noción de un cuerpo diablo con la actividad depredadora de las brujas? Ya lo comentamos. Son asistentes del diablo, y su modus operandi remite a una directiva precisa: recuperar la sangre que ha sido derramada tras el proceso de alumbramiento. Un tema clásico de las ontologías indígenas, que revela coincidencias entre las características europeas y las de origen prehispánico de las brujas: depredación, captación, captura, rapto. Consideremos entonces esas nociones en acción a partir de una secuencia última del Carnaval, particularmente espectacular, en San Bartolo Tutotepec, Hidalgo, llamada la octava, que se verifica cada año una semana después del fin, tal como la presencié el 12 de marzo del 2019. ${ }^{6}$ Como en toda la sierra, el Carnaval es el momento de celebración de los flujos menstruales que implican un acto violento: agresión, coito sádico, alumbramiento sangriento, creación de monstruos excéntricos. Los hijos del Viejo nacen ya muertos, sacrificados. Son los "pequeños ancestros", disfrazados de diablos, que circulan entre los actores durante las performances del ritual.

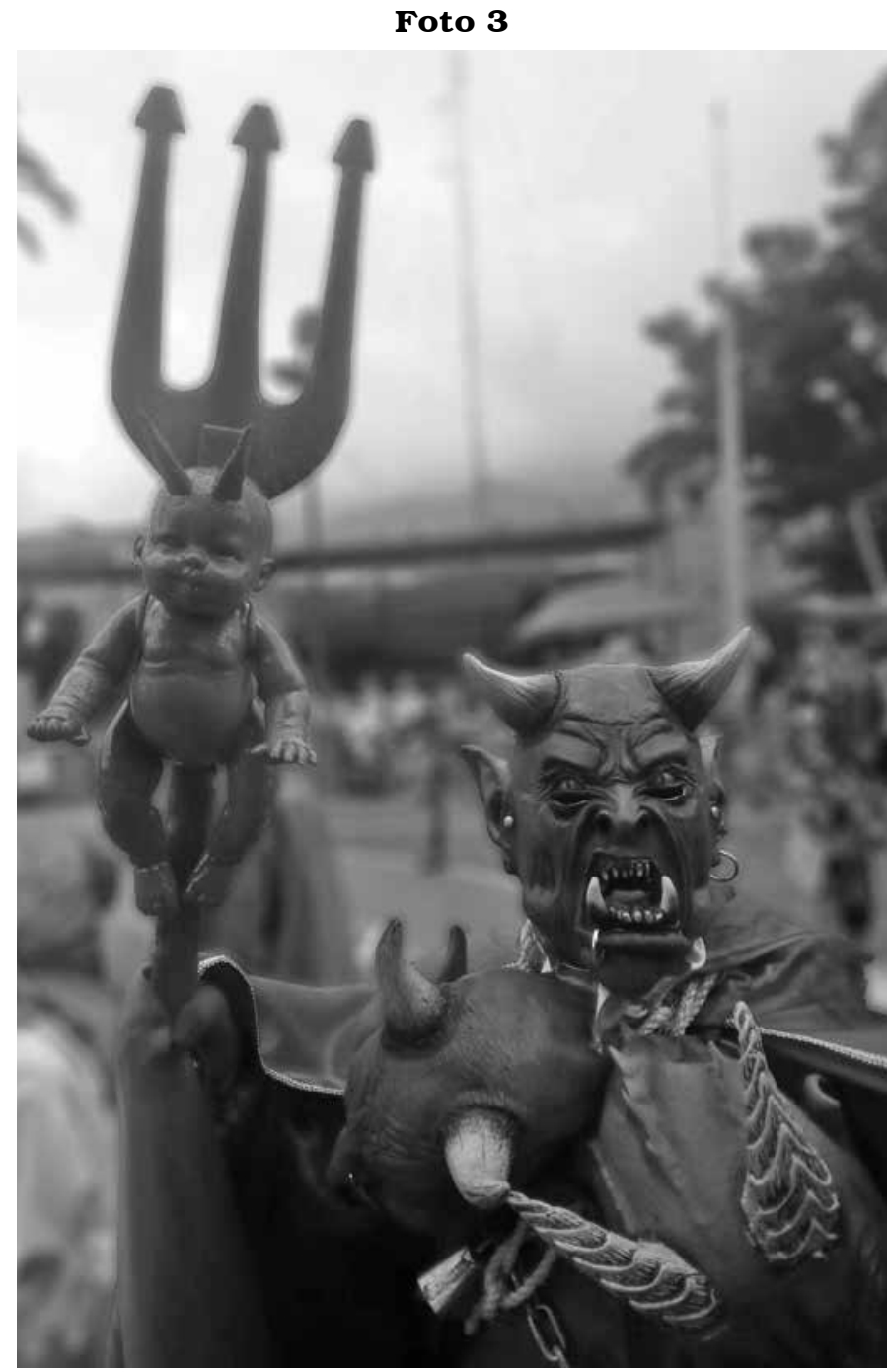

El diablo y su progenitora, tras un acto de decapitación. La octava del Carnaval, San Bartolo Tutotepec, Hgo. Foto: J. Galinier

Ahora, ¿cómo describir la articulación de esta performance con la lógica de la endoalteridad que estamos explorando? Todos los datos acumulados remiten a lo siguiente: la división corporal entre parte alta vs. baja, parte de dios vs. parte del diablo. Es decir, como lo hemos enfatizado, la endoalteridad de los actores es una parte constitutiva de la embriología, y una dimensión

5 Uno de los cantos eróticos más difundidos recalca el papel rector del Viejo en esta manifestación descontrolada de su priapismo dominador: 1. hoki zoni hoki zoni / 2. ẽmpu tata kon nda hmũza / 3. hoki zoni hoki zoni / 4 . empu nana kon nda thũme (1. No llores, no llores / 2. Tu padre viene con un plátano / 3. No llores, no llores / 4 . Tu mamá viene con un bolillo) (Galinier, 1990: 361).

6 El significado de la octava se relaciona con la idea de que el ciclo del Carnaval implica una reduplicación posritual, suerte de síntesis del guion de las performances, con los mismos disfraces, para reactivar su dinámica hasta el año siguiente, a pesar o gracias a su carácter sangriento. Tiene lugar en la cabecera municipal, predominantemente mestiza, y los actores son en parte oriundos de las comunidades otomíes de la región. Puede asociarse con la tentativa fracasada de reiteración de la subida de un Viejo al Palo Volador de San Miguel, pueblo del municipio de San Bartolo Tutotepec, al final del Carnaval. Su caída y su "muerte" resulta ser la condición paradójica de su repetición el año siguiente (Galinier, 2009b: 
estructural con el cual los vivos tienen que conformarse. En el Carnaval, desde el primer contacto, los actores conocidos como Viejos entran en este proceso y sufren sus consecuencias en términos biológicos, fisiológicos, afectivos y cognitivos. El diablo no sólo es a la vez magister y dominus, sino que es el polo extremo de una serie de agencias, a través de las cuales se expresa su nde (boca), es decir, su pulsión caníbal. Las brujas, como asistentes del diablo, trabajan por su cuenta, visto que se presentan a través de una infinidad de avatares, que aparecen a la vista en la vitrina del Carnaval.

La fecundación de las mujeres se verifica mediante la sangre de la luna (khi zãna), de tal modo que t'üzithũ reproduce en miniatura las funciones del ancestro apical. Alrededor de la captación de la sangre existe un combate ritual que muestra cómo el derrame de sangre es indisociable de eventos kinestésicos de diversa índole: coreografías espontáneas, música y cantos en un contexto erotizado. En la construcción del embrión se manifiesta una fuerza perjudicadora, lo que presenta semejanzas significativas con la noción de feto agresivo, en el mundo andino, tal como lo ha conceptualizado Tristan Platt (2001) y aplicado Palmira La Riva (2012). ${ }^{7}$ Esto permite aclarar, bajo nueva luz, las cuestiones centrales de la embriogénesis, el estatus ontológico de los seres que pueblan los espacios salvajes y domésticos, y explicar la problemática de los géneros. En los Andes, como lo señala La Riva, "el inacabamiento humano del recién nacido" explicita directamente su papel como enemigo, en primer lugar, para la propia parturienta (La Riva, 2012: 20). En el caso otomí, no tenemos un equivalente a la construcción andina de la humanidad del niño después de un "duelo" inicial, puesto que la dimensión ajena, "diabólica", del ser es constitutiva de su identidad. No obstante, encontramos concepciones análogas en los Altos de Chiapas, como lo comenta Hülsewiede, a propósito de la "muerte" del pene en el cuerpo de la mujer, que generará un niño y su doble, un Doppelgänger, la placenta, enterrada como parte del cuerpo socializado, condenada a "morir", separada de su alter ego al nacer, pero a la que quedará íntimamente ligada a lo largo de su vida (Hülsewiede, 1997: 114).
A través de la octava, el tratamiento de la endoalteridad resulta un modo de explicitación de la muerte como un proceso vital fruto de un coito sádico. La muerte funge como condición sui generis del proceso vital actuando en el Carnaval, en particular por la presencia de kat'üyãntö (niños disfrazados con los mismos atuendos que los šihta), como "natos muertos", los cuales recuerdan la génesis de esos t'üzithũ como dobles ontológicos del Viejo. ${ }^{8}$

La condición de existencia del infans es que nazca "muerto", como ser potente, fruto de un acto sacrificial y condenado a desaparecer tras un acto ambivalente. El ritual de alumbramiento significa la construcción de una tanatogénesis como requisito indispensable de recreación de la sociedad. En la octava del Carnaval de San Bartolo Tutotepec, todas las performances hacen las veces de concentrado de los eventos anteriores, que enseñan las distintas secuencias del proceso ritual: cacería, captura, decapitación, coito cósmico, embarazo, desvitalización del cuerpo del Viejo y reanimación en el marco del "hospital", probablemente fecundada por el Viejo. El Carnaval como ritual mortuorio es una repetición de la Fiesta de Muertos, a través de una serie de actos bélicos, de descontrol, bajo la custodia de la policía, y actos sacrificiales, como la decapitación. La secuencia de la mujer embarazada cubierta de sangre pone de relieve esta odisea violenta cuyo altar es el cuerpo de la mujer (véase foto 4 ).

\section{La ontogénesis como tanatogénesis}

En el mundo otomí, la aclimatación del complejo europeo de las brujas y la identificación entre instancias de origen prehispánico y colonial dentro de una misma lógica cultural se basa en la reversibilidad de los rasgos ontológicos de los actores mediante el ritual de autoamputación, condición esencial para pensar en la actualidad la intrusión de la cultura transnacional, mexicanay estadounidense dentro del espectro cosmológico indígena, como lo observamos en tiempos de la globalización. Los efectos de la exoalteridad se agregan al poder destructor de la endoalteridad como componente letal del cuerpo persona, tendido hacia la muerte.

49-55). Para un análisis detallado del Carnaval en el municipio de San Bartolo Tutotepec, consúltese Gallardo Arias (2009 y 2012). Para las comunidades de Pueblo Nuevo y Chicamole, véase Rainelli (2019).

7 Saúl Millán propone además sugerentes similitudes entre la noción de feto agresivo de Platt y la concepción de los antiguos nahuas de la presencia de un guerrero enemigo capturado en el cuerpo de la mujer grávida (Millán, 2019: 110).

8 Recordemos que en la terminología de parentesco otomí se verifica una duplicación de los nombres de los parientes de nivel Ego $+x$, es decir de los más antiguos, y Ego -2 (be’to, "principio"), que señala el reinicio del ciclo de la patrifiliación. Familiarmente, se acostumbra llamar a los infans šihta, "viejos". Los t’üzithũ, que surgen durante el ritual de alumbramiento, pertenecen ipso facto como neonatos al mundo de los muertos (Galinier, 1990: 127-131). 


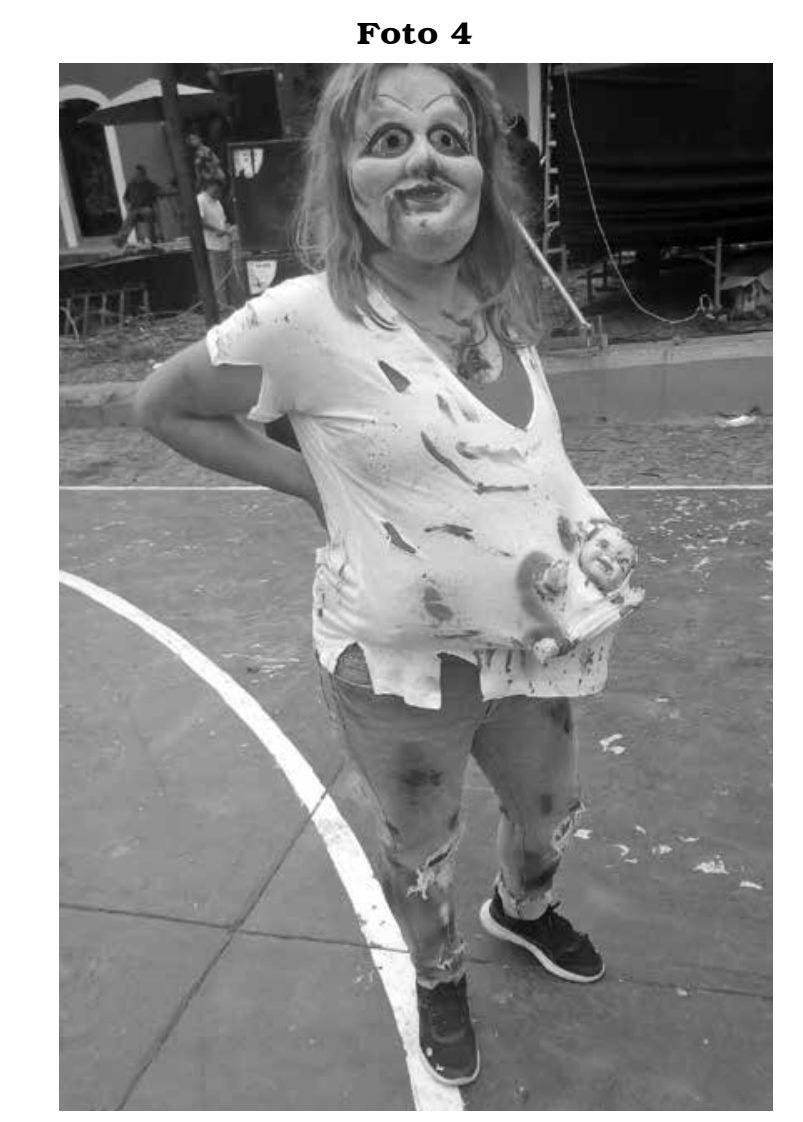

Mujer embarazada mostrando los estigmas de una fecundación violenta. La octava del Carnaval, San Bartolo Tutotepec, Hgo. Foto: J. Galinier.

Si la endoalteridad plantea el problema de la cohabitación con seres inquietantes, en el caso de los parientes la depredación puede suceder de manera inmediata, in situ, o después de un recorrido celeste, pero siempre pasando por la forma aviar. La mayor paradoja es que los otomíes, a pesar suyo, siguen teorizando la endodepredación mediante imágenes y símbolos que remiten a la tradición europea de la brujería, según un procedimiento selectivo de compartimentación que a veces confunde lo endógeno y lo exógeno, lo europeo con lo indígena, pero que sí mantiene vigente la idea de una escisión entre dos corrientes culturales antagónicas, y la reversibilidad de las ontologías locales mediante procesos políticos frágiles de construcción y de renegociación de la identidad nativa. Si, como lo afirman Nutini y Roberts para Tlaxcala, donde han analizado de manera exhaustiva el complejo del blood sucking witchcraft, la alteridad se construye a partir de la primera menstruación, la endoalteridad otomí se edifica a partir de que el diablo se manifiesta como legislador y dueño de los cuerpos femeninos (Nutini y Roberts, 1993). La depredación es la otra cara de un imperativo fisiológico: recuperar la sangre menstrual, considerando que las primeras reglas coinciden con la necesidad de reequilibrar la cantidad de fluidos corporales. Por eso, todas las mujeres son potencialmente disponibles para actuar como brujas. Por ende, la endoalteridad implica un proceso de transformación física, lo que explica la ausencia de una solución de continuidad entre humanos y animales, híbridos y excéntricos, mediante la actividad de las brujas, como vectores de las traslaciones espaciotemporales de las fuerzas que gobiernan el funcionamiento del cuerpo humano.

En suma, a partir de los materiales analizados, resulta más claro que el síndrome de la bruja se presenta como una fórmula invertida de la consanguinización de los alteri, extranjeros o enemigos, por la siguiente razón: por un lado, tenemos los procesos institucionales y rituales de incorporación de los forasteros, oriundos de las distintas etnias representadas en el inframundo y que incluye a los mestizos, tal como aparecen en el Carnaval. Estos extranjeros se agregan a los ancestros nativos: hacen parte del panteón de difuntos que regresan entre los vivos, una vez al año, al pueblo. Por otro, existen los consanguíneos o afines del primer tipo (es decir miembros de la comunidad) que resultan ser enemigos potenciales, según una variación pendular en función de su deseo de manducación o de captación de sangre. Eso da a entender que la reversibilidad de las ontologías, las mutaciones de una especie a otra, de un género a otro, con la eventualidad de regreso al estado inicial, es una característica consustancial a la génesis de los humanos. La alteridad se vuelve entonces la condición sine qua non de la fabricación de la comunidad, tanto a nivel sincrónico, como diacrónico. A nivel sincrónico, la alteridad con frecuencia está presente más allá de las fronteras de la comunidad (en San Lorenzo Achiotepec, las ofrendas "contaminadas" que de manera ritual se abandonan en el monte, se depositan del otro lado del lindero que separa los estados de Hidalgo y Veracruz). En el mismo ritual, el espacio convencional, en la cumbre del cerro tât'öhö, está delimitado por una clase de cordón sanitario en el cual están colgadas figurillas de papel ceremonial llamadas "soldados". A nivel diacrónico se ubican todas las etnias acumuladas en el inframundo, ancestralizadas y, por lo tanto, vueltas enemigos.

La octava expresa entonces, de manera violenta, cómo el sacrificio de los niños resulta ser la condición de la revitalización del cosmos. De hecho, su capital hemático está concentrado y almacenado para permitir una perfusión constante del Viejo o de uno de sus avatares, como el paciente tendido en una cama (la cerveza Corona funciona como equivalente simbólico de $k h i$, la sangre/esperma). 
Por ende, la coreografía del Carnaval demuestra cómo este evento sirve de escenografía de los twists and turns de la endoalteridad. Pone en escena a todos esos neoparientes integrados en una sola etnia. Resulta que todos los sujetos son hermanos, nacidos de un ancestro apical, el Viejo. Pueden ocupar el papel de cazador o de presa, masculina o femenina, dominador o dominado, receptor o proveedor, ya que el Carnaval instala el mundo de la selva en medio de los vivos, como lo comprueba la octava. La escena del hospital expresa a la vez la necesidad de alimentar al Viejo, o uno de sus avatares, mediante la transfusión de una sustancia vital y letal a la vez. De allí el séquito de figuras excéntricas; la mujer grávida, cubierta de sangre, así como el personal médico se relacionan tanto con la muerte como con la vida (a través de las crías monstruosas que andan cargando) (foto 5).

La demanda del Viejo permite regular los flujos de sangre a partir de una hematipología que valora las sangres en función de sus cualidades específicas, en particular las de los recién nacidos. Finalmente, su reciclaje permite que el Viejo recobre un máximo de fuerzas para cumplir con su deseo de rejuvenecer a la humanidad, de allí el carácter obsesivo de su exigencia: "Vengo a regar mi sangre" (o mi esperma). En el arte oratoria ritual se traslapan dos niveles semánticos que subrayan la necesidad de distribuir un flujo, instrumento de reproducción de las generaciones, tras la duplicación alterna de los marcadores de la ancestralidad, de yântö a kat'üyãntö (del Viejo al infans), la "pequeña cabeza de viejo".

\section{Conclusión}

En toda la Sierra Madre, la cuestión de la alteridad aparece como un interrogante obsesivo de los otomíes, que sirve de hilo conductor de sus experiencias rituales, en particular del Carnaval, como puesta en escena de ontologías alternativas. La experiencia de la endoalteridad, es decir, de la incrustación de ciertos componentes ajenos en la constitución del sujeto, es un fenómeno cotidiano, a raíz de las situaciones oníricas, de la embriaguez, del coito, relacionado con la presencia del nahual (pöni) o del guajolote, en términos de coesencia y de copresencia. Existe un constante proceso de circulación de los elementos que constituyen la identidad de los sujetos, internos y externos. No puede concebirse cualquier ipseidad sin tener en cuenta estas constelaciones transgenéricas, transespecíficas.

La endoalteridad es un concepto que permite, entonces, abarcar a la vez una dimensión constitucional

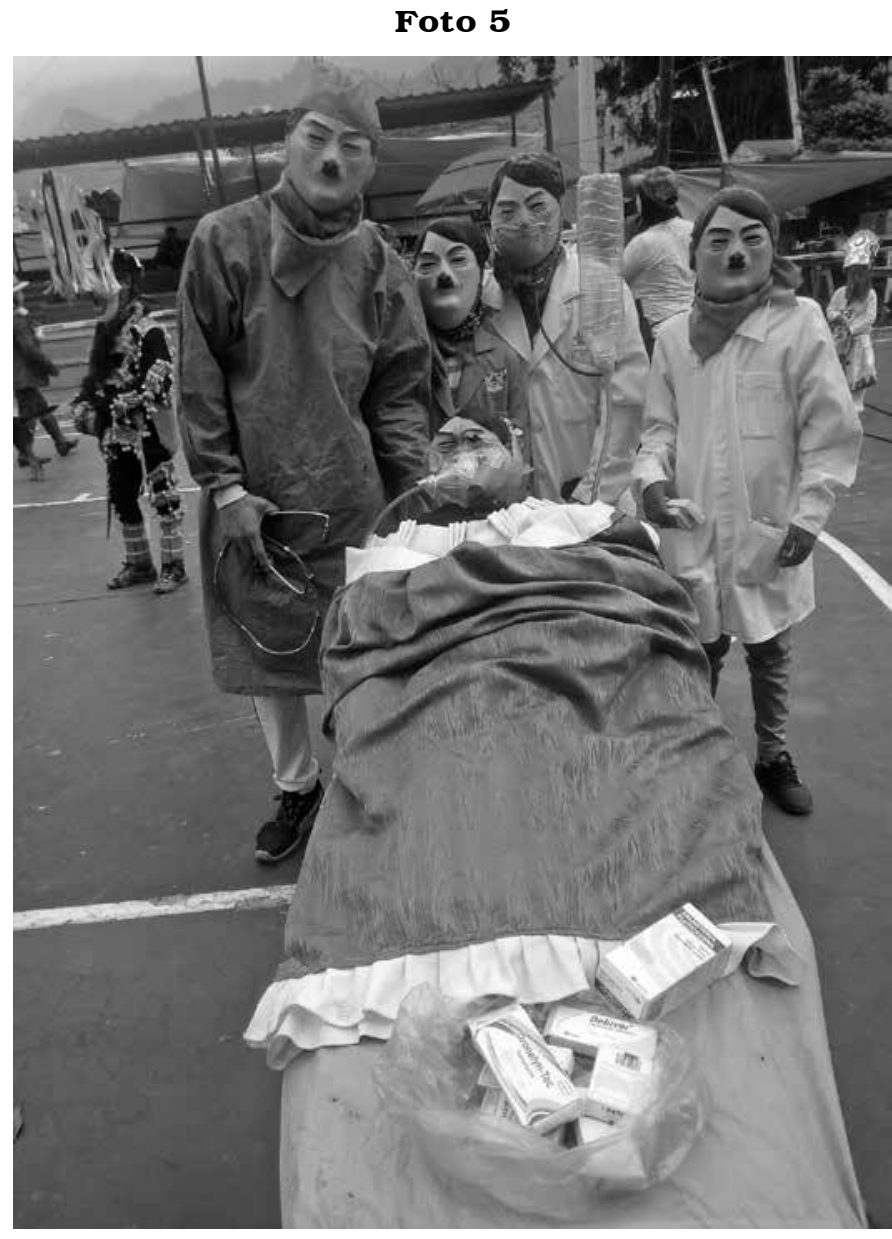

Reanimación del Viejo, el ancestro primordial, mediante la inyección de cerveza Corona.

La octava del Carnaval, San Bartolo Tutotepec, Hgo. Foto: J. Galinier.

(yo es otro) y dinámica del sujeto (mediante procesos de contaminación de la persona por fuerzas dirigidas de adentro hacia afuera y viceversa), lo que obliga a los vivos a mantener cierto nivel de coalescencia entre las fuerzas que generan el bienestar, las cosechas, la erradicación del mal. Todas las generaciones aparecen confundidas en el mismo panorama étnico transgeneracional. La presencia congenital constante de un alter en el cuerpo orienta el sistema de decisiones hacia una esfera externa a la colectividad de los humanos. La endoalteridad es un concepto que tiene un eco directo a nivel de la ética otomí. Todo el sistema de negociaciones se orienta a crear y mantener un modus vivendi aceptable, considerando que una fracción de cuerpo físico y mental obedece a una legislación externa, global, de control de la humanidad, de retribución de su tributo en sangre.

A partir de la octava del Carnaval, resultan explícitos los fundamentos de la teoría otomí de la unifiliación, la cual utiliza el lenguaje de los humores para relacionar 
todos los humanos con el Dueño del Mundo, mediante la circulación de su sangre/semen. El imperativo hipotético del Viejo, en el sentido kantiano, consiste en exigir -bajo la forma de sacrificios-la sangre que él ha regado para sus "hijos". Su propia voluntad se negocia a través de la de sus avatares, los cuales aparecen cubiertos del líquido sacrificial. Al nacer, ya son definitivamente muertos, igual que el Viejo, en el momento de derrame de su sangre, de expresión de su máxima potencia, se vuelve totalmente desvitalizado. De manera espectacular, la metáfora clínica del Carnaval de San Bartolo Tutotepec expresa la fuerza de esta ideología.

La búsqueda de sangre remite a un síndrome que rebasa los imperativos normativos del parentesco, teniendo en cuenta que la alianza sí permite organizar estrategias de sobrevivencia, de prestigio, a veces a través de relaciones asimétricas como en el padrinazgo, pero no protege de ninguna manera de los ataques de brujas ni de todos los actores del inframundo tal como aparecen celebrados en el Carnaval. El territorio de lo propio es abierto, sin fronteras, lo que expresa su vulnerabilidad. La simbólica del alumbramiento gira alrededor de la eclosión de la muerte. El ritual de génesis, Carnaval, no es más que la explicación mayúscula de cómo se duplican los muertos. Las brujas participan de esa necesidad de alimentar constantemente el creador. Lo que interroga sobre los deseos de esas figuras: ¿cuál sería entonces el punto de vista de las brujas sobre el mundo, sobre su relación con los vivos y en particular con las criaturas más débiles? Carecemos de explicaciones directas y de discursos indirectos.

Por último, la construcción bipartita del Yo explica la manipulación a distancia de los sujetos de parte de zithũ. En consecuencia, el síndrome de la bruja trastorna las categorías, las clasificaciones de género, y pone el énfasis en la labilidad de ésas. De facto, la porosidad de las envolturas corporales se verifica a través de la doxa y de la praxis chamánica. Justifica la circulación de fuerzas patógenas desde afuera hasta adentro. He señalado cómo esta estructura frágil del sujeto se relaciona con la movilidad de los componentes de la persona: espíritu, sombra, "aire". Estos componentes son compartidos con no humanos, separados espacial (nahuales) y temporalmente (ancestros), tantos seres que circulan en la noche, orientados hacia la depredación. Una noche que funciona como pantalla y escena de las agresiones del diablo. Por cierto, la problemática de las brujas genera todavía un abanico de preguntas sin respuestas sobre la política del parentesco, y las crisis comunitarias en el mundo indígena en tiempos de la globalización.

\section{Fuentes}

Caro Sevilla, Víctor

2019 Puxk'uai. Un ser en la oscuridad en la cosmovisión otomí, con una presentación de Jacques Galinier, Instituto Humboldt de Investigaciones Interdisciplinarias en Humanidades/Universidad Intercultural del Estado de Hidalgo/El Colegio del Estado de Hidalgo, México.

Davies, Nigel

1990 "Dualism as a universal concept: Its relevance to Mesoamerica", en Rudolf van Zantwijk, Rob de Ridder y Edwin Braakhuis (eds.), $M e$ soamerican Dualisms. Symposium, ANT. 8 of the 46th International Congress of Americanists, Amsterdam 1988, RUU-ISOR, Utrecht, pp. 8-14.

FreUd, Sigmund

1933 Neue Folge der Vorlesungen zur Einführung in die Psychoanalyse, Internationaler Psychoanalytischer, Leipzig, Viena y Zurich.

Galinier, JACQUes

1987 Pueblos de la Sierra Madre. Etnografía de la comunidad otomí, Instituto Nacional Indigenista/Centre d'Etudes Mexicaines et Centraméricaines, México.

Galinier, Jacgues

1990 La mitad del mundo. Cuerpo y cosmos en los rituales otomíes, Universidad Nacional Autónoma de México/Centro de Estudios Mexicanos y Centroamericanos / Instituto Nacional Indigenista, México.

Galinier, Jacgues

2009a "Yo es otro: marcadores corporales de la (de)negación en el ritual otomí (México)", en Manuel Gutiérrez Estévez y Pedro Pitarch (eds.), Retóricas del cuerpo amerindio, Iberoamericana Vervuet, Madrid, pp. 213-226.

Galinier, Jacgues

2009b El espejo otomí. De la etnografía a la antropología psicoanalítica, Instituto Nacional de Antropología e Historia/Comisión Nacional para el Desarrollo de los Pueblos Indígenas / Centro de Estudios Mexicanos y Centroamericanos, México.

GALINIER, JACQUES

2019a "Una contienda asimétrica: Zithũ, sepulturero otomí de la teoría antropológica”, en Dimensión antropológica, año 26, vol. 75, pp. 7-19.

Galinier, JaçUes

2019b "Ontologías reversibles. Las 'brujas' y las formas elementales de la depredación entre los otomíes del México oriental", en Gerardo Fernández Juárez y Francisco Gil García (coords.), Sinestesias. Brujería y hechicería en el mundo hispánico, Abya-Yala, Quito, pp. 365-390.

Gallardo, Patricia

2009 Ar xoke. El carnaval entre los otomíes de San Bartolo Tutotepec, Universidad Autónoma del Estado de Hidalgo (Cuadernos de la tradición), Pachuca.

Gallardo, Patricia

2012 Ritual, palabra y cosmos otomí, yo soy costumbre, yo soy de antigua, Universidad Nacional Autónoma de México-Instituto de Investigaciones Históricas, México. 
Hülsewiede, BRigitte

1997 "Alter Ego Vorstellungen in Kontext von Geburtsriten und Sexualität in Mesoamerica", en Religionsethnologische Beiträge zur Amerikanistik, LIT, Münster, pp. 105-120.

La Riva González, Palmira

2012 "Au plus près du corps. La construction sociale du corps-personne dans une communauté des Andes du Pérou", tesis de doctorado, Universidad París Nanterre, Nanterre.

LEISTLE, BERNHARD

2013 Anthropology and Alterity, Routledge, Londres.

LORENTE, DAVID

2011 La razzia cósmica. Una concepción nahua sobre el clima. Deidades del agua y graniceros en la Sierra de Texcoco, Centro de Investigaciones y Estudios Superiores en Antropología Social, México.

Martínez González, Roberto

2011 El nahualismo, Universidad Nacional Autónoma de México, México.

Millán, Saúl

2019 "La alteridad a través del espejo: origen e identidad en la narrativa nahua", en Estudios de Cultura Náhuatl, vol. 57, pp. 109-160.

Nutini, Hugo

Y JOHN ROBERTS

1993 Bloodsucking Witchcraft: An Epistemological Study of Anthropomorphic Supernaturalism in
Rural Tlaxcala, University of Arizona Press, Tucson.

Olavarría, María Eugenia,

Cristina Aguilar y Érica Merino

2009 El cuerpo flor. Etnografía de una noción yoeme, Universidad Autónoma Metropolitana/

Platt, Tristan Miguel Ángel Porrúa, México.

2001 "El feto agresivo. Parto, formación de la persona y mito-historia en los Andes", en Anuario de Estudios Americanos, vol. 58, núm. 2, pp. 633-678 <https://doi.org/10.3989/aeamer. 2001.v58.i2.218>.

Rainelli, Federica

2019 "Oltre la maschera. Usi e significati del corpo nella pratica rituale otomì (Huasteca sud, Messico)", tesis doctoral, Universidad de $\mathrm{Pa}$ dua, Venecia "Ca' Foscari”, Verona/Ecole des Hautes Etudes en Sciences Sociales-cerma.

RIMBAUd ARTHUR

1958 OEuvres, texto revisado por Paul Harmann, Mercure de France, París.

VAN ZANTWIJK, RUDOLF,

RoB DE RIDDER Y EDWIN BRAAKHUIS (EDS.)

1990 "Introduction", en Rudolf van Zantwijk, Rob de Ridder y Edwin Braakhuis (eds.), Mesoamerican Dualisms. Symposium, ANT. 8 of the 46th International Congress of Americanists, Amsterdam 1988, RUU-ISOR, Utrecht, pp. 1-7. 